\title{
农科无机及分析化学课程学习状况的调查与分析
}

唐小兰 ${ }^{*}$, 刘英菊

华南农业大学材料与能源学院, 广州 510642

摘要: 针对无机及分析化学课程的学习状况, 对相关专业的部分学生进行了抽样调查。调查结果发现: 大一学生对 于这门公共基础课程的学习兴趣低, 学习动力欠缺, 学习方式单一, 学习方法有待训练。针对上述调查结果, 本文 对存在的问题也提出了解决对策, 探索了结合我校实际情况选择相应的教学与学习模式以及培养学生自主学习能力 的途径。

关键词: 无机及分析化学; 学习动机; 自主学习能力

中图分类号: G64; O6

\section{Investigation and Analysis on Learning Situation of Agricultural Inorganic and Analytical Chemistry Course}

\author{
Xiaolan Tang *, Yingju Liu \\ College of Materials and Energy, South China Agricultural University, Guangzhou 510642, P. R. China.
}

\begin{abstract}
In this paper, based on learning situation of agricultural inorganic and analytical chemistry course, a questionnaire survey was conducted among some freshman students in related majors. The results show that the students have minimal interests in the study of this public basic course, lacking learning motivation and flexible study methods. Thus, they need training in learning methods. We also suggest the corresponding solutions to the existing problems above, and explore how to cultivate students' autonomous learning ability by choosing the corresponding teaching and learning modes.
\end{abstract}

Key Words: Inorganic and analytical chemistry; Learning motivation; Self-learning ability

无机及分析化学课程是农林院校一门重要基础课程, 每年要对全校生物技术、食品安全、材 料科学与工程等二十多个专业 3 千多学生讲授这门课程, 授课人数多, 学生的化学学科基础水平差 异较大, 授课教师队伍存在从教授到讲师不同教学经验的差别。因此, 对学生的学习状况展开调查 进行统计分析, 针对学习状况中存在的问题, 从如何提高学生学习的效果这一目的出发, 在教学设 计上探讨采用怎样的教学模式激发学生的学习兴趣; 从学习方式方面入手, 探讨采用怎样的方式提 高学生的学习投入程度, 从而达到培养学生自主学习能力的目的。

\section{1 无机及分析化学课程调查问卷的设计与实施}

本次调查主要从影响学生学习效果的外部因素以及内在因素两个方面设计了问卷题目, 其中外

收稿: 2020-05-29; 录用: 2020-07-26; 网络发表: 2020-08-26

“通讯作者, Email: tangtx11972@163.com

基金资助: 2019 广东省质量工程项目 “无机及分析化学” 教学团队 
部因素涉及了对教材的认可度、教师教学方式、教学风格、师生互动程度等因素; 学生的内在因素 涉及了学生的学习动机、学习方式、学习时间、对课程内容的理解程度等方面。

本次调查对象是已经修完这门课程的大学一年级学生, 从授课教师了解了考试成绩情况后, 从 授课对象的 25 个专业中, 抽取了 20 个自然班, 抽取的班级选择入学成绩为三个不同层次的不同学 院的专业, 同时也考虑了本门课程考试成绩好、中、差三个层次的不同专业班级; 发放自制的调查 问卷 600 份, 问卷中有两道题是开放题, 其他题为客观选择题。回收的有效问卷为 562 份, 有效回 收率为 93.6\%, 问卷采用 Excel2010 处理。

\section{2 无机及分析化学课程学习状况调查问卷的结果统计与分析 \\ 2.1 影响学习效果的外部因素数据统计与分析}

(1) 根据调查问卷统计, 目前受调查学生所接受的授课方式(问卷第 6 题), 以 PPT 宣讲为主, 偶 尔提问这种方式所占比例为 $48.16 \%$; 而 PPT 宣讲与黑板书写兼用, 同时组织学生讨论这种方式占 $30.48 \%$; PPT 宣讲与黑板书写以及看影像资料占 $16.38 \%$; 采用线上辅助教学方式所占比例仅 $4.98 \%$, 说明在课堂上引导学生探索思考问题的教学方式以及线上辅助教学方式相对利用较少。

(2) 学生对课堂学习节奏的适应程度(第 7 题)。目前课程的授课学时数为 48 学时, 调查结果显 示, 有 $47.98 \%$ 的学生认为学时少, 上课节奏快, 希望增加学时; 而 $46.56 \%$ 学生认为不需变化, 也有 $5.46 \%$ 认为可以减少。将近一半的学生跟不上课堂的节奏, 这跟多数学生缺少预习和复习总结学习环 节有关。而在当今信息时代的大环境下, 怎样的学习模式才能有效地把学生从玩网游、闲聊微信的 时间中挤出一些课程学习需要的时间呢? 这是我们需要思考解决的问题。

(3) 授课班级人数的多少对学生参与课堂的影响程度(第 8 题)。结果显示, $69.19 \%$ 学生希望能够 小班(小于 65 人)上课, 只有 $9.89 \%$ 学生愿意选择大班(大于 90 人)上课, 而 $20.88 \%$ 学生认为无所谓。 结果说明, 多数学生期望能够小班上课, 但因为教学班级多, 教师相对不足, 因此, 对于人数多的 教学班级, 如何调动学生参与课堂讨论, 开展小组协作式学习方式, 这是我们急需研究探讨的问题。 为此, 我们也做了一项课后以微信或 QQ 方式开展讨论与交流方式的调查(第 12 题), 结果表明有 $68.64 \%$ 的学生希望以这种方式在课后讨论交流化学问题。

(4) 对目前教材所选内容的评价与看法(第 9 题)。结果显示 $19.35 \%$ 的学生认为教材内容浅显易 懂, 而 $34.68 \%$ 的认为内容多而杂, $45.96 \%$ 的认为需要补充学科前沿与联系实际的内容。目前本校学 生采用的是本校教师编写的、由中国农业出版社出版的《无机及分析化学》教材, 经过近六年的使 用实践, 已经做了两次修订, 但从调查结果来看, 有 $45.96 \%$ 的学生期待教材做学科前沿与联系实际 的内容的补充修订, 因此, 本课程的教改项目团队需要对教材做进一步的修订工作。

(5) 哪些原因会影响学生对课程的喜爱程度(第 10 题)。结果表明, $17.79 \%$ 的学生认为是教师的 气质与人格魅力引发对课程的喜欢, 而有 $29.66 \%$ 的学生认为受教师幽默风趣的教学语言吸引而喜欢 课程, 也有 $39.83 \%$ 的学生认为出于自己对课程的好奇与兴趣而喜欢, 还有 $12.71 \%$ 的学生因教师授 课枯燥无趣而不喜欢这门课程。由此可见, 除了学生自身对知识的需求以及对课程的喜好, 教师的 教学方式也会在一定程度上影响到学生的学习兴趣。

(6) 课堂上师生互动程度(第 11 题)。统计结果表明, $20.86 \%$ 的学生期望参与课堂讨论并喜欢老 师提问, 而 $59.13 \%$ 的学生不喜欢被老师提问, 只有 $20.01 \%$ 的学生希望主动回答问题。 $59.13 \%$ 的学 生不喜欢被老师提问, 说明课堂提问这一方式, 不能有效地在课堂互动中采用。如何提高学生在课 堂的参与度, 充分发挥学生学习的主体性, 这是今后我们在教学设计上需要深刻思考的问题。

(7) 教师对学生学习方法指导的程度(第 13 题)。结果表明, 有 $65.44 \%$ 的学生认为教师在课堂上 有穿插学习方法的传授, 但占用时间比较少; $18.57 \%$ 的认为没有; $15.99 \%$ 的认为比较多。大学一年 级学生由于受中学阶段的应试教育, 以及传统 “传递-接受型” 的教学模式的影响, 学生的自主学习 能力以及独立探究分析能力相对欠缺, 所以, 多数学生认为教师在课堂上传授学习方法的时间应该 
有所增加。

\section{2 影响学生学习效果的内在因素的统计与分析}

(1) 学生学习这门课程的学习动机(第 2 题)。结果显示, 有 $63.03 \%$ 的学生只是出于完成学分的 目的来学习, 而只有 $28.11 \%$ 的学生是因为对课程有较强的求知兴趣来学习的, 也有 $8.86 \%$ 的学生是 根本不想学习该课程。决定学习效果的主要因素还是学生的内在动机, 调查表明多数学生是出于完 成学分的目的来学习, 这是一个外加动机, 但如果外加动机不能引起学习兴趣, 就不会有持久性, 必 然会影响到学习效果。

(2) 学生对课程理解程度的差异(第 3 题)。结果显示, $9.75 \%$ 的学生觉得课程很难懂; $50.04 \%$ 认 为较难, 但通过老师的分析答疑能理解; $38.52 \%$ 认为难度一般, 自学可理解大部分; 有 $1.7 \%$ 认为容 易。一半的学生对课程理解有一定难度, 希望通过老师的指导答疑来理解, 说明一年级学生的自我 分析探索的能力相对欠缺, 这要求教师在教学环节中，需要有相应的学习方法的指导。

(3) 学生对课程的需求程度(第 4 题)。结果显示, $12.82 \%$ 的学生期望只要能通过该课程考试即可; $36.75 \%$ 的学生希望老师多讲习题, 掌握课程考核大纲要求; 还有 $50.42 \%$ 的学生期望补充化学前沿知 识, 扩展思路与视野。从学生对课程的需求来看, 我们的课堂教学在一定程度上还不能满足不同层 次学生对课程的不同需求, 原因是大班授课, 不能很好地做到因材施教, 不能充分满足学生个性化 发展的需求。

(4) 学生学习方式的调查情况(第 5 题)。结果显示, 在授课阶段, $23.62 \%$ 的学生在课外的学习方 式只是完成作业; $65.17 \%$ 的学生在完成作业外偶尔复习教材与课件; 只有 $7.41 \%$ 的学生会找课外参 考资料做补充习题; 另外, $3.8 \%$ 的学生会与同学开展讨论。调查结果说明, 学生课外投入课程的学 习时间相对较少，尤其是学生采用自我探究型学习方式的时间较少。

\section{3 改善学习状况的对策分析}

根据以上的调查结果分析, 我们了解了大学一年级学生对于无机及分析化学这门课程的学习状 况, 针对调查分析提出的问题, 我们在教学上必须采取相应的措施来应对这些问题, 以改进我们的 教学, 从而逐渐改变目前学生学习兴趣较低、学习动力不足、学习方式单一、学习方法有待训练的 现状。

\section{1 调查学生的心理状态以便 “对症下药”}

要想学生学, 首先要让学生对课程有兴趣, 那么任课教师在开课初期需要对学生做一个调查, 以了解学生的学习心理状态, 了解学生不喜欢课程的原因是哪些, 是自己的基础水平, 还是自己的 学习能力, 还是早期的心理因素的影响, 还是教师的上课方式等。目前, 这项工作借助我校的在线 教育综合平台可以顺利地实施, 只要在课程教学这一模块中的课程问卷中, 设置问卷, 选课的学生 在平台回答问卷, 平台就可记录问卷情况。任课教师根据问卷结果做好相应的记录, 以便在今后的 教学中进行区别对待。

\section{2 从教师和学生两个角度分别来改善学生学习兴趣较低的状况}

如果是来自学生方面的原因, 可以采用把教学班进行分组, 每个分组考虑由兴趣高和兴趣低两 个层次的学生组合, 同时也兼顾一下学生的自愿原则, 这样可以以小组协作互助的方式带动学生的 学习兴趣, 对于基础较差的学生, 还需要个别辅导, 以激励他的学习。目前这项工作可以通过我校 的在线教育平台顺利完成，在选课学生管理栏目页面中选择学生组设置，就可对学生进行分组设置; 如果是教师的原因, 那么需要教师加强自我学习, 提升自己的教学水平, 可以通过多听有经验的同 行教师的课, 学习有经验的教师的教学方式, 同时也可以咨询学生的意见来改进自己的教学, 以此 来增强对学生的吸引力。

\section{3 改变教学策略以激发学生学习动机和主动性}

美国教育专家杰里·布洛菲(Jere Brophy)提出, 学习动机是一种在学习环境中通过个人的经验积 
累而习得的能力 ${ }^{[1]}$ 。张庆林曾指出发展学生内在学习动机的最主要手段是让他们 “学有所得” , 帮 助缺乏学习动力的学生最好办法是帮助他们在学习上取得进步, 并在进步中体验一种内部的自我奖 励 ${ }^{[2]}$ 。

那么什么样的教学策略可以激发学生的内在动机呢? 根据认知心理学的学习动机理论, 人的认 知需要是学习的内在动机, 比外加动机更有推动力、更持久。那么如何激发学习动机呢? 首先, 教 师需要把握好教学难度, 从大多数学生所在的起点出发, 选择恰当的背景知识, 比如电影、电视节 目、社会新闻等, 创造相应的教学情境。比如: 从 “三鹿奶粉” 事件出发引导学生探讨如何运用酸 碱滴定分析法进行蛋白质含氮量的精准测定, 从化学分析方法所带来的社会价值这一角度出发, 激 发学生进一步思考这种测定方法的局限性, 从而探索更完善的测定标准。其次, 教师要促使学生积 极投入学习任务。这要求教师设计一些特定的教学任务与学生的实验课程紧密联系。比如, 在讲解 定量分析的准确度与精密度等相关概念时, 结合学生所做实验 “甲醛法测定铵盐的含氮量”, 安排学 生课前学习这部分内容的线上视频(概念的讲解), 布置任务要求学生结合自己所做实验的数据, 探 讨如何提高分析结果的准确度这一问题, 在课堂上, 我们就可以按照学生分组, 每组选派一名代表 进行总结发言, 最后通过课堂讨论、教师的总结陈述, 完成对准确度与精密度等概念以及提高分析 准确度方法的掌握, 这样学生通过自我探索性的学习, 通过对实际问题的分析讨论, 培养了学生分 析和解决问题的能力; 另外在学习小组间展开的学习讨论方面的竞争比赛, 也可以在平时成绩计分 中给予相应计分, 这样使更多学生在学习中体验到学习的快乐与成就感。

\section{4 在小班开展翻转课堂的改革试点以改变学习方式的单一化}

“小班课教学” 模式是世界一流大学教学实践中广泛应用、行之有效的一种重要的组织形式 ${ }^{[3]}$ 。 小班课教学使学生有更多机会参与课堂讨论, 更有利于师生的交流与互动, 更利于学生主体意识的 培养, 因此, 在教学任务安排允许的前提下, 尽可能采用小班教学方式。然后, 我们将在小班教学 中试行 “翻转课堂” 的改革试点, 同时与非试点班进行比较研究, 以评价试行教学模式的效果, 这 样我们可以合理利用现有的网络教学资源, 选择相应的内容作为翻转课堂的课前学习资源, 有效调 动起学生的课外时间, 这样在有限的课内学时, 可以实施问题式、启发式和师生互换角色式等教学 方式 ${ }^{[4]}$ 。比如, 在讲解精密度与偏差的概念时, 有关五种偏差公式的意义与运算方式, 可以通知学生 在线上学习这部分的讲课视频, 布置学生结合自己已经做过的酸碱比较滴定分析实验的实验结果, 思 考怎样运用这几个公式的计算结果来判断实验结果的精密度的好坏。在课堂上, 就可以展开分组讨 论, 学生总结陈述。在这个学习过程中, 学生不仅仅是简单地认知了五种公式的运算形式, 而是更 多地开始思考它们之间的区别、它们有什么用、怎样去应用, 因此, 通过这样的教学过程, 我们的 目的不再是简单传授知识, 更多的是训练学生的思维方法, 在翻转课堂中通过学生与教师的角色互 换, 使学生体验授课过程, 同时也要求学生对所讲解的内容较好地掌握。这样一方面可以调动学生 准备的积极性, 另一方面给学生一个展现个人能力与团队合作的平台 ${ }^{[5]}$ 。学生通过自学、准备讨论 方案、参与讨论等多种自主性学习方式增加了学习投入，从而进一步提高了学习效果。

\section{5 利用微信与 $Q Q$ 群等互联网模式加强师生交流与互动}

根据问卷调查的结果显示, 有 $68.64 \%$ 的学生希望课后用 QQ 群与微信的方式这种方式在课后讨 论交流化学问题。由于师资有限, 这门公共基础课能够小班上课的班级毕竟有限, 而且翻转课堂对 学生的基础与能力有较高要求, 不适合全面推广, 所以需要利用微信以及 $\mathrm{QQ}$ 等信息交流方式来促 进师生的交流, 以便及时掌握学生学习状况, 针对出现的问题给出相应的学习方法指导。比如笔者 曾利用 91 速课这个微信公众教学平台, 在课前推送预习内容, 布置课堂讨论需要事先查阅的资料, 部分章节布置自我检测题, 以此检查督促学生的学习; 当然, 目前, 雨课堂、优慕课等在线课程平 台, 都是我们在课堂讲授时, 根据教学需要, 借以辅助的信息化教学手段。

综上所述, 在当今信息化的时代背景下, 教师要改变以往在课堂上灌输式的角色形象, 教学活 动的设计与实施, 不应只是按照教学进程完成一定的教学任务, 而应从学生的学习效果出发, 以学 
生为中心, 在教学设计、组织方式及教学方法上, 充分体现学习者的需要和基础, 将其与课程教学 的总体目标、教与学的过程及环节有机结合在一起, 激发学生自主学习和探究的愿望与潜能 ${ }^{[6]}$, 把 学生培养成 “生成知识的人”。

\section{参 考 文 献}

[1] [美] 巴克利, 伊丽莎白·F. 双螺旋教学策略. 古显奎, 顾关, 唱飞镜, 邵䂀瑶, 译. 广州: 华南理工大学出版社, 2014: 8 .

[2] 张庆林. 高效率教学. 北京: 人民教育出版社, 2002: 107-111.

[3] 宋傘. 中国大学教学, 2015, No. 11, 28.

[4] 吴硕, 刘志, 宿艳, 王秀云, 刘哲, 张明旭. 中国大学教学, 2015, No. 1, 54.

[5] 高峻, 陈彦逍, 李万舜, 谢川. 大学化学, 2018, 33 (11), 47.

[6] 史静褱, 涂冬波, 王纾, 吕宗伟, 谢梦, 赵琳. 清华大学教育研究, 2011, 32 (4), 23. 